\title{
Consent for Pluripotent Cell Use for Therapy
}

\author{
Erica C. Jonlin ${ }^{1}$
}

Published online: 12 May 2015

(C) Springer International Publishing AG 2015

\begin{abstract}
Translational research in human pluripotent stem cells presents a new paradigm for the development of therapeutics in that the source materials originate from human beings. Pluripotent stem cell researchers administering informed consent from the specimen donors must strive for clarity with respect to a number of non-trivial issues. Careful consideration is warranted regarding derivation of cell lines and their future uses, the extent and length of the relationship between the researchers and the donors, confidentiality, and ownership of results. This review covers the elements of informed consent, and the issues they raise, for consenting donors of embryos and somatic specimens used to derive induced pluripotent stem cells.
\end{abstract}

Keywords Pluripotent stem cell therapies · Informed consent - Tissue donation - Embryo donation - Translational research $\cdot$ Drug development

\section{Introduction}

Pluripotent stem cell-derived therapies present a new paradigm for drug development because the therapies are derived from human beings. Not only is the therapeutics development enterprise dependent on the willingness of patients to enroll in

This article is part of the Topical Collection on Stem Cells: Policies from the Bench to the Clinic

Erica C. Jonlin

ejonlin@u.washington.edu

1 Institute for Stem Cell and Regenerative Medicine, University of Washington, 850 Republican St., Box 358056, Seattle, WA 98109, USA clinical trials and receive experimental pluripotent stem cellderived products, but it is also dependent on the willingness of human beings to donate the originating specimens. Hence, careful consideration of the substance of the consent for donation of pluripotent stem cells is warranted.

While it is true that we have used human cells and tissue for therapy for some time, we have not until very recently derived cell lines from one individual that could ostensibly be administered to many other persons. Whole organ transplantation and transplantation of hematopoietic stem cells such as umbilical cord blood and bone marrow have become established treatments. However, the organ or hematopoietic cell product is designed for a single patient recipient, and it is minimally processed prior to administration. Umbilical cord blood stem cells may be expanded briefly in culture prior to administration, but are not extensively manipulated [1]. In contrast, pluripotent stem cells arising from a single donation will be grown in culture and differentiated, possibly reengineered before or after differentiation, and then administered to potentially many patients. Eventually, we may have a number of off-the-shelf pluripotent stem cell-derived products, from a relatively small number of donors, that will last indefinitely and that can be used in many recipients, to treat perhaps a variety of diseases.

At a joint NIH-FDA meeting at the NIH in 2011, "Pluripotent Stem Cells in Translation: Early Decisions," [2] attendees were warned to be very careful of early decisions made when embarking on a translational research path. Among those critical decisions is the original source of stem cells. Whether the cells come from leftover clinical specimens, from tissues obtained for research purposes, or from embryos no longer needed for reproductive purposes, the translational researcher's ability to develop the cells into a therapeutic product depends not only on their own talent and expertise, and properties of the cells, but also on what use(s) the donors 
consented to. A research team would not want to spend the extraordinary time, effort, and funds required to develop a cell line for therapeutic purposes only to discover that the original informed consent did not in fact cover that use and that they must halt the translational research program.

For purposes of this paper, we will focus on informed consent for donation of (1) excess embryos to derive human embryonic stem cell lines (hESC lines) and (2) somatic specimens used to derive induced pluripotent stem cell lines (iPSC lines).

\section{The Elements of Informed Consent}

Because the use of pluripotent stem cells for therapy remains experimental, consent to donate specimens for pluripotent stem cell therapeutics development falls under the jurisdiction of research regulations. In the USA, consent form requirements are codified in the Code of Federal Regulations, at 45 CFR 46 (also known as the Common Rule) and at 21 CFR 50, Subpart $\mathrm{B}$ (FDA regulations); international regulations summarize consent requirements in the International Conference on Harmonization (ICH) E6 [3-5]. The NIH Guidelines for Human Stem Cell Research has additional requirements for informed consent for donation of embryos for hESC line development; investigators wishing to list newly derived hESC lines on the NIH Stem Cell Registry must demonstrate that these elements were in the informed consent forms signed by embryo donors [6]. Informed consent requirements and how they apply to donation of a specimen for pluripotent stem cell research are summarized in Table 1 (excess embryo donation) and Table 2 (somatic specimen donation). Table 3 lists additional informed consent items recommended by Aalto-Setala et al. [7••] and by the International Society for Stem Cell Research (ISSCR) [8] for donors of specimens used to derive iPSC lines.

\section{Basic Components of Informed Consent}

\section{Purpose of the Research}

Generally, for the scientific team, the purpose of obtaining a leftover embryo or other specimens for pluripotent stem research is to derive a pluripotent stem cell line and collect foundational knowledge regarding pluripotency and tissue regeneration. Thus, the emphasis in a consent form would be derivation of immortalized pluripotent stem cell lines, including a clear explanation of what an immortalized cell line is, and development of basic knowledge. Additionally, embryo donors need confirmation that their embryos will not be allowed to develop in culture and/or used to create a pregnancy.

Only a miniscule number of donations are likely to become the basis of a therapeutic product. Notably, of the over 300 human embryonic stem cell lines listed on the NIH Stem Cell
Registry [9], only two lines are currently in clinical development, NIH lines 0043 and 0041, developed by WiCell Research Institute and ViaCyte, respectively. WiCell Research Institute's H1 hESC line (also known as WA01) was employed in Geron's phase 1 spinal cord injury clinical trial of hESC-derived oligodendrocytes [10]; this product, called OPC1, is now under continuing development by Asterias Biotherapeutics for spinal cord injury and neurodegenerative diseases [11]. In September 2014, ViaCyte initiated a clinical trial for diabetes (clinicaltrials.gov identifier no. NCT02239354) based on ViaCyte's CyT49 hESC line, differentiated into a pancreatic progenitor cell product (called PEC01 ), and encapsulated into a proprietary drug delivery device, Encaptra $^{\mathrm{TM}}$, which is implanted under the skin of patients with diabetes [12]. Not on the NIH Registry is Ocata Therapeutics' hESC line, MA09. Ocata Therapeutics (formerly Advanced Cell Technology (ACT)) is running several clinical trials for degenerative diseases of the eye including Stargardt's Disease and macular degeneration. In deriving hESC lines, ACT started with 8-10 cell embryos from which they extracted a single blastomere for hESC line production; for this reason, MA09 was not eligible for the NIH Stem Cell Registry, which only accepts lines derived from the inner cell mass of blastocyst stage human embryos $[6,13]$.

Although so few hESC lines may end up as the starting material for a therapy, it is nevertheless essential to inform donors that a therapeutic product may be developed in the course of the basic research. Indeed, a key reason why individuals consider donating specimens to pluripotent stem cell research is because they hope that it may do some good and help others $[14 \bullet \bullet, 15 \bullet]$.

\section{Procedures to Be Followed}

When the donated specimens are excess embryos no longer needed for reproductive purposes, the only research procedure for the donors is informed consent to make the donation. When the donated specimens are differentiated cells that will be induced to pluripotent stem cells, the consent form must describe the procedures for obtaining the specimens-for example, whether the specimens will be left over from a clinically-required procedure (such as a blood draw), or obtained from a medical procedure (such as a skin biopsy), performed for the specific purpose of making induced pluripotent stem cells.

Donors also need to give consent for review and use of their medical records for research purposes, if this information will need to be accessed. The consent form must specify whether a single snapshot of the medical record will be taken at the time of donation and provided to the research team, or the research team will have continuous access to the donor medical record. Implications of medical record use are discussed in more detail below. 


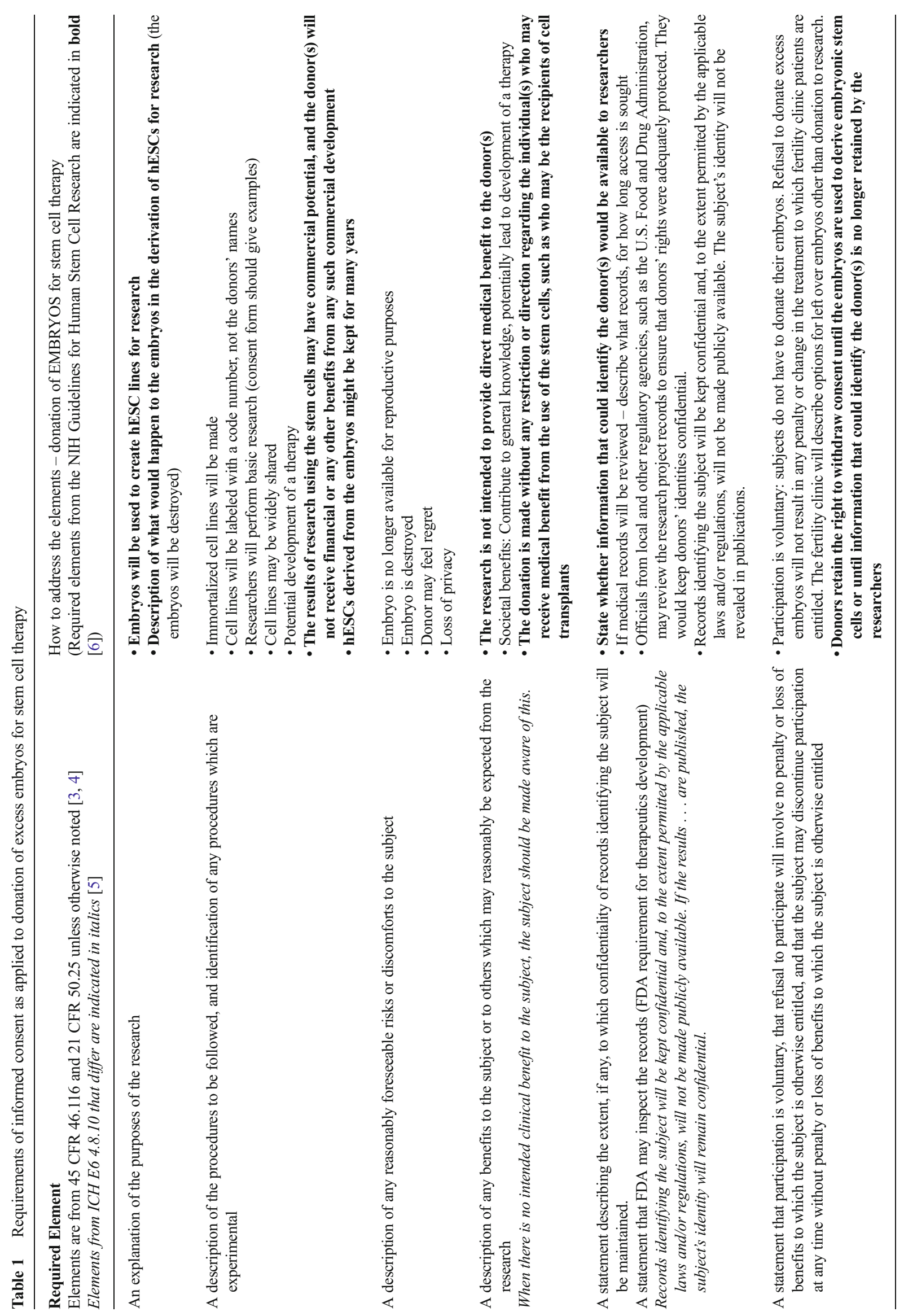




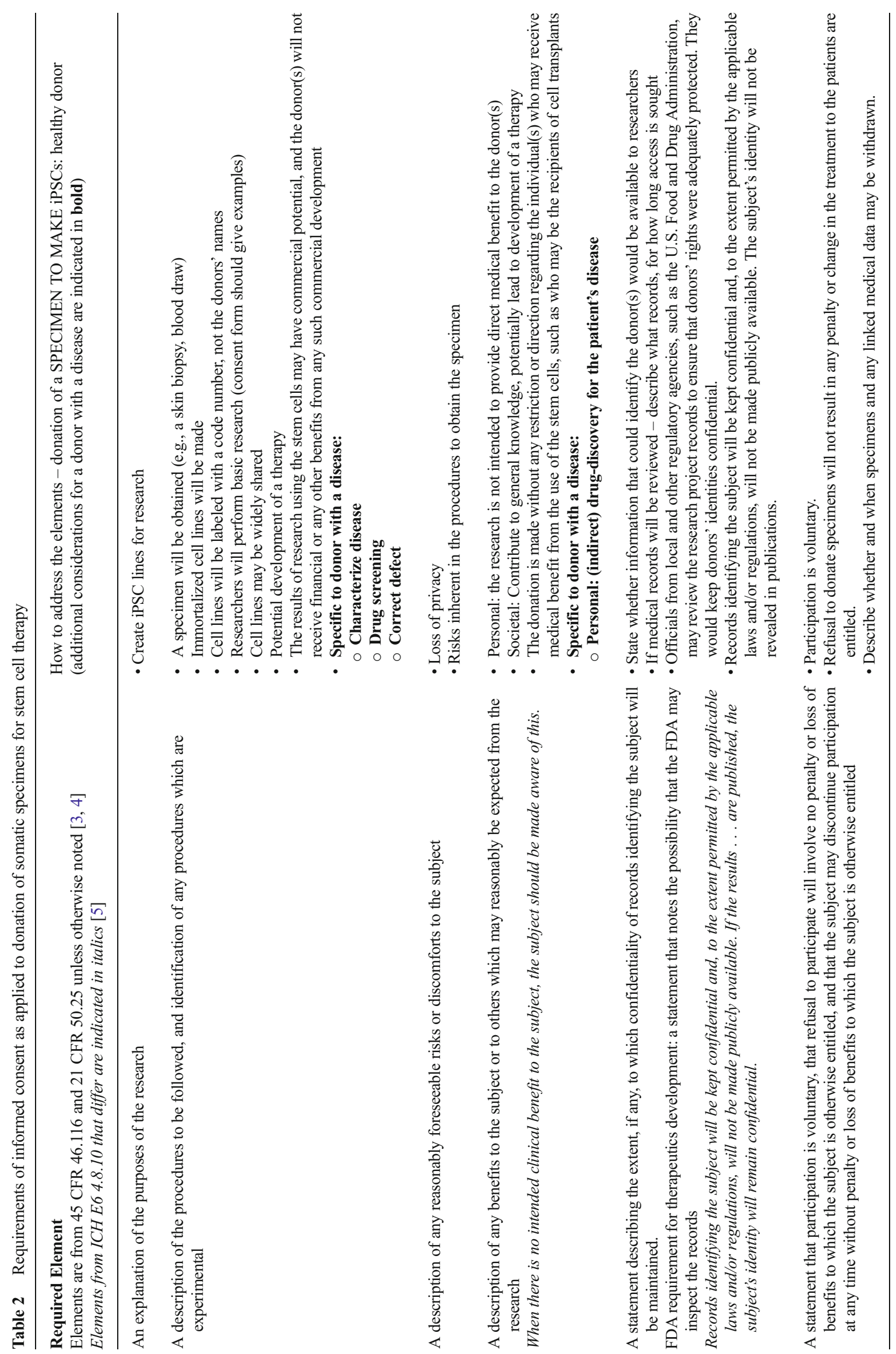


Table 3 Additional recommended consent elements for iPS cell lines
Research procedures for which Aalto-Setala et al. recommend specific consent from donors of specimens used for iPSC research $[7 \bullet \bullet]^{\mathrm{a}}$
Consent elements recommended by the ISSCR Clinical Translation Guidelines of 2008, regarding donation of specimens for allogeneic use (Recommendation 3) [8]

- Genetic modification of cells

- Injection of iPS cells or derivatives into nonhuman animals, including injection into the brain

- Large-scale genome sequencing

- Sharing cell lines with other researchers, with appropriate confidentiality protections

- Patenting scientific discoveries and developing commercial tests and therapies, with no sharing of royalties with donors (a) That cells and/or cell lines may be subject to storage. If possible, duration of storage should be specified;

(b) That the donor may (or may not) be approached in the future to seek additional consent for new uses, or to request additional material (blood or other clinical samples) or information;

(c) That the donor will be screened for infectious and possibly genetic diseases;

(d) That the donated cells may be subject to genetic modification by the investigator;

(e) That with the exception of directed altruistic donation, the donation is made without restrictions regarding the choice of the recipient of the transplanted cells;

(f) Disclosure of medical and other relevant information that will be retained, and the specific steps that will be taken to protect donor privacy and confidentiality of retained information, including the date at which donor information will be destroyed, if applicable;

(g) Explanation of what types of genomic analyses (if any) will be performed and how genomic information will be handled; and

(h) Disclosure that any resulting cells, lines or other stem cell-derived products may have commercial potential, and whether any commercial and intellectual property rights will reside with the institution conducting the research.

\footnotetext{
${ }^{a}$ From Aalto-Setala K, Conklin BR, Lo B: Obtaining Consent for Future Research with Induced Pluripotent Cells: Opportunities and Challenges. PLoS Biology. February 2009; 7(2). e42. doi: 10.1371/journal.pbio.1000042 [7••]

${ }^{\mathrm{b}}$ Reproduced with permission from the International Society for Stem Cell Research (ISSCR). Guidelines for the clinical translation of stem cells. (2008). http://www.isscr.org/clinical_trans/pdfs/ISSCRGLClinicalTrans.pdf. Accessed August 23, 2010 [8]
}

If relevant, the donors must be informed that a cell line derived from their donation may be shared with other investigators, at other institutions, and even with commercial entities. Donors uncomfortable with widespread sharing of their specimen, and/or use of the specimen to derive a commercializable product, should not make the donation. With the publication of the widely acclaimed, New York Times Bestseller, The Immortal Life of Henrietta Lacks [16], the general public has become more savvy about research with specimens [15•, 17], and is aware of the scientific reality that cell lines can be made that may be widely shared, and long outlive the individual from whom the cells were initially derived.

\section{Reasonably Foreseeable Risks or Discomforts}

For the donors, the physical risks of pluripotent stem cell research are relatively trivial. The real risks are psychosocial and emotional. For example, because the embryo will be destroyed as part of the research, a risk that some donors express is the sense of finality, a sense of loss [14••]. Destruction of the embryo is indeed a "societal risk" of this research and the reason for the ethical controversy.

Risks to privacy and confidentiality are perhaps the more significant risks of pluripotent stem cell research. It is likely that any pluripotent stem cell line, especially one under consideration for a therapeutic product, will be extensively genotyped. For transplantation purposes, there is a need to determine the HLA haplotype, as well as the presence of mutations in the line that may warrant it unsuitable as a source of tissue for a given organ. For example, a cardiac mutation in hESC-derived cardiac tissue could render it compromised as a cardiac therapy, unless the mutation was corrected. If whole genome sequencing is done on an iPSC line or its derivatives, personal genetic information of the donor will be revealed, including disease risk. As demonstrated in Gymrek et al. [18], there is the risk that the identity of the originating donor(s) could be determined. Gymrek et al. illustrated the reidentification of male DNA donors and their families via a combination of surname inference, the use of recreational genetic genealogy databases, and free, publicly accessible Internet resources. Hence, donors do need to be forewarned of the albeit small risk of disclosure of their identity, and disclosure of genetic information.

Because for every embryo there are two biological donors, donors of embryos may be less at risk for reidentification through sequencing since the embryo genome is a unique genome, a complex combination of the two biological parents. However, as in iPSC line sequencing, disease risk genes that may run in the family will be revealed.

A 2013 policy document from the American College of Medical Genetics and Genomics (ACMG) [19] recommended that subjects be informed if, during sequencing, a deleterious mutation that is medically actionable is found in one of 57 specific genes known to cause a serious disease. However, this policy has been controversial, and many geneticists have 
themselves pushed to allow specimen donors to opt out of getting incidental, unexpected genetic information [20].

\section{Benefits Which May Reasonably Be Expected}

At this stage of development, the benefits of pluripotent stem cell research are purely to society. The donor of a specimen used for pluripotent stem cell research cannot be promised any personal benefits, other than personal satisfaction.

With the August 2013 approval of a clinical trial in Japan to test an autologous iPSC-derived product, it may be soon possible to begin to assess the personal benefits of iPSC-derived therapeutics. Masayo Takahashi's pilot study will assess the safety and feasibility of the transplantation of autologous iPSC-derived retinal pigment epithelium (RPE) cell sheets into patients with wet-type age-related macular degeneration [21].

Currently, an active area of research is the use of patient specimens to generate iPSC lines for disease modeling and drug screening. Gene-targeting tools offer the possibility of correcting the mutation in a patient's iPS cells, as was recently demonstrated by Li et al. [22], who achieved the precise correction of the dystrophin gene in iPS cells from a patient with Duchenne muscular dystrophy. Clinical trials of corrected autologous cells are still far off in the future.

\section{The More Complex Issues of Informed Consent for Pluripotent Stem Cells for Therapy}

\section{Voluntary Participation and the Right to Discontinue Participation}

Under 45 CFR $\$ 46.116$ (a) (8), the informed consent must include, "A statement that participation is voluntary... and the subject may discontinue participation at any time without penalty or loss of benefits to which the subject is otherwise entitled." [3] When the participant's involvement is only donation of a specimen, voluntary participation involves the right not to donate. Because the regulations are vague, the right to discontinue participation may or may not be interpreted as the right to withdraw the specimen from the research study. It is up to the investigative team or their institutional review board (IRB) to decide whether and at what point the specimen may be withdrawn.

In his essay, "Respecting Donors to Biobank Research," Tomlinson [23] argues that a donor, whose specimen is already stored, should be able to opt out. For example, if a donor objects to specific uses of their materials, Tomlinson postulates that the biobank should be able to destroy all donated materials, all derived data, and all individual health information at the donor's request. Those involved in biobank research have not resolved this issue, a scenario which appears to weigh the importance of the autonomy of the donor against the value of the research efforts [24]. However, a juncture may be reached at which withdrawal may be a moot point. Once cell lines have been widely shared, withdrawal may not be possible. Additionally, after the cells have been differentiated into the desired cell type, withdrawal could be deemed unreasonable. Given the current estimated drug development price tag of over $\$ 1$ billion, a company developing an hESCderived product would not want to take on the financial risk of commercialization if a donor could withdraw consent. Certainly after a therapeutic product has been transplanted into patients, withdrawal would be impossible [24].

While it may be extremely unlikely that a donor would desire withdrawal of their specimens, return of specimens was the net result in the widely publicized case of the Havasupai Indian tribe who objected to Arizona State University's use of their specimens [25]. When they discovered that ASU had been using their specimens to perform genetic research studies that they found to be offensive, the tribe sued the university. Although the tribal members had provided consent for the use of their specimens for research, the consent had not been "informed"; they had believed that they were consenting to diabetes research only. In the settlement, ASU apologized, provided monetary compensation, and returned the remaining specimens to the tribe. This experience only underscores the importance of clarity in the consent form and in the informed consent process.

In general, people who want to donate a specimen to research appear committed to their donation and do not display an expectation of being able to withdraw it. For example, couples who seriously considered donating excess embryos to research expressed a desire to advance technology and human health, and to help others, as seen in our own research [14.• $]$ and in a systematic analysis of multiple surveys of fertility clinic patients' attitudes [26]. Regarding iPSC research, in focus groups with patients at Johns Hopkins Hospital, Dasgupta et al. found that patients were generally supportive of iPSC research and also expressed a desire to help others. The interviewees did express concerns about whether or not research would adhere to the terms of signed consent forms [15•]; this again emphasizes the importance of being up-front about the potential uses of donated tissue for iPSC research.

Regarding embryo donation, the NIH Guidelines for Human Stem Cell Research recommend that donors not be allowed to withdraw their embryos after they are used to derive embryonic stem cells [6]. Perhaps the NIH saw this statement as necessary to protect the significant investment that the research enterprise (both public and private) will have made by the time a pluripotent stem cell line has been developed. Indeed, it is advisable that the consent form be clear about whether and when withdrawal is no longer possible.

Given that a pluripotent stem cell line is no longer the specimen it was when it was donated, it may be argued that the donor really has no authority to request its withdrawal. Indeed, as will be discussed below, courts have found that a 
donor has no ownership over a cell line that originated with one of their specimens.

\section{Confidentiality of Records}

As in all human subject research studies, specimens are labeled with a code number, the donor's name removed. Unless the pluripotent stem cell lines are to be anonymized, a master list of code numbers linked to identifying information is typically maintained in a password-protected database. There are several important reasons for not anonymizing specimens when pursuing pluripotent stem cell research. When developing hESC lines, in order to be able to list a line on the NIH stem cell registry, it is necessary to provide to the NIH the template consent form for reproductive treatment that the originating embryo donors signed, in order to prove that the embryo was made for reproductive purposes (i.e., not for research purposes) [6]. Without maintaining a link to identifying information, this would not be possible.

Additionally, researchers working with hESC lines may want to leave open the possibility of recontacting the embryo donors for medical/health information should FDA request it. As discussed in Jonlin [27], fertility clinic patients are exempt from FDA's Tissue Donor Eligibility Requirements, and do not undergo all of the FDA-required infectious disease testing required of other tissue donors. Most notable of these is the screen for Creutzfeldt-Jakob disease (prion diseases), for which the FDA requires an extensive interview with the would-be donors [28]. Currently, the FDA is silent on whether they would extend the fertility patient exemption when the patients' excess embryos are used to make hESC lines and downstream products. If not, it is possible that hESC researchers engaged in therapeutics development would want to be able to recontact embryo donors for testing and to interview them for exposure to prion diseases. As an aside, Wilkerson et al. [29] noted that although donors of gametes used to create a pregnancy undergo all of the infectious disease testing, the gamete donors may not have given their consent for research use of resulting embryos. Whether the gamete donors should be recontacted is an open question.

It is worth commenting that recontacting donors, particularly embryo or gamete donors, raises serious ethical issues. In donating their excess embryos to research, many embryo donors are seeking closure; recontacting them many years after the embryo donation for the sole purpose of asking them about their prion exposure may be deemed highly inappropriate and an invasion of privacy $[14 \bullet \bullet]$. Aalto-Setala et al. [7••] recommend that consent for recontacting be obtained from somatic cell donors when they are first consenting to the use of their specimen for pluripotent stem cell research; it may be advisable to do the same with embryo donors.
When patient specimens are used to make iPSC lines for specific diseases, the specimens are often linked to medical records so that the relationship between the molecular defects and the manifestations of their disease may be studied. Clearly, even for normal donors, maintaining a link between iPSC lines and medical records would be of great value. Continuous access to donors' medical records would require informed consent and may require an intermediary, such as a clinician, who would provide medical information to the research team in a coded fashion to maintain the confidentiality of the donor.

Saha et al. [30••] have proposed that donors of specimens used for pluripotent stem cell research be made partners in the research enterprise. Operationally, stem cell donors would allow investigators continued access to their medical records, enabling scientists to look for correlations between patient disease phenotype and cellular and tissue abnormalities observed in the lab. In exchange for allowing researchers extensive access to their records, donors would be kept apprised of progress in the research. Saha et al. posit that partnering with stem cell donors could help build trust between research subjects and researchers. Patient advocacy groups could provide an entrée for researchers seeking partnerships.

Kaye et al. [31•] have similarly proposed a "participantcentered initiative" (PCI) model for biomedical research which takes advantage of the latest functionalities in information technology. Interactive tools, such as social networking, could be used to build long-term partnerships between research participants and researchers, allowing for use of specimens and transfer of medical information, including specific informed consent for its use. The authors argue that participant recruitment, retention, and confidence in the research enterprise would all be strengthened by this model.

Medical record access and even partnering with donors of valuable pluripotent stem cell lines could prove especially advantageous in those rare cases when a pluripotent stem cell line is used for transplantation. Awareness of the originating donor's ongoing medical and family history could prove essential in decision-making regarding the use of their derived pluripotent stem cell line and subsequent differentiated tissue if it is used for repeated transplantations [7••]. We have been asked by donors if they would retain any liability for their donation; we have answered "no" [14••]. However, given the plethora of lawsuits in the USA in particular, it is not entirely surprising that a donor would have concerns that they could be sued for not revealing a medical problem in their family that "contaminates" the cell line that has been administered to people as a therapy.

\section{Ownership}

Partnering with donors of stem cell materials begs the question of whether the specimen donors are told the specific results of the research. It also introduces the need to clarify who 
owns the results of the research. This becomes particularly relevant if a therapeutic product results.

There is no regulatory requirement that the donors be told the results of the research with their specimen. For reasons not entirely understood, success rates of making hESC lines from embryos are low. While laboratories making stem cell lines do not publish their success rates, among the research community, it is known that they are far below $50 \%$. To explain to an embryo donor that their embryo did not result in a line could be a great disappointment. On the other hand, telling them that a line was made follows a partnership model and does exemplify respect for the donor. Researchers may fear that the donors would then expect to be involved in deciding how that line is used.

While the NIH guidelines do not comment on whether an embryo donor should be informed of the results of the research with their embryo, the guidelines do require that the consent form make clear, "That the donation was made without any restriction or direction regarding the individual(s) who may receive medical benefit from the use of the hESCs, such as who may be the recipients of cell transplants [6]."

In the USA, legal precedent regarding ownership of cell lines goes back to the infamous case of John Moore, a patient with hairy cell leukemia. In the course of his treatments at UCLA, unbeknownst to Moore, Moore's doctors discovered unique properties of Moore's cells, and eventually established and patented a cell line, which they called the Mo cell line. After a number of years, during which time Moore returned to UCLA multiple times in order to provide specimens ostensibly for his clinical care, Moore discovered the researchers had made a valuable cell line from his specimens. He sued the researchers and the Regents of California (Moore v Regents of California), and the case eventually went to the Supreme Court of California. In their final decision, the Court found that the UCLA investigators had violated their duty to obtain informed consent. However, the court did not find that Moore had any property rights to the cells obtained from him, or to the Mo cell line specifically [32].

Similarly, Washington University v Catalona found that research participants do not have ownership rights to biological materials they voluntarily donate to research. In this case, research participants wanted their specimens to move with Dr. Catalona when he changed research institutions. The court determined that the specimens were gifts to research at Washington University, not to Dr. Catalona, and it was Washington University that owned them [33]. The Catalona case supported the concept that specimen donation is a permanent gift, and as such is no longer under the jurisdiction of the donor.

Addressing the issue of ownership head-on is an additional consent requirement that NIH guidelines has delineated, "That the results of research using the hESCs may have commercial potential, and that the donor(s) would not receive financial or any other benefits from any such commercial development [6]."

\section{What Do We Owe the Donors?}

In contrasting the extraordinary value of the HeLa cell line, made from Lacks's cells without her consent, with the relatively low economic status of Henrietta Lacks's descendents, The Immortal Life of Henrietta Lacks reignited the question as to whether tissue donors should be compensated for their donation, should it become the source of commercially valuable materials [16]. As eloquently discussed in Truog et al. [34••], there are ethically compelling reasons not to offer compensation to the donors, particularly when the tissue is a leftover clinical material. First, although the donors have provided the "raw materials" necessary for the development of the cell line, it is the scientific expertise and the intellectual efforts of the investigators that have made the material of value. Indeed, once a specimen has been manipulated - whether turned into a pluripotent stem cell line and subsequently differentiated, and/or genetically modified - it cannot truly be said to be that of the donors.

Second, as noted by Michael Sandel in What Money Can't Buy [35], acts of generosity (such as the donation of tissue, in this case) paradoxically become less appealing to those considering such an activity when there is a monetary incentive (e.g., "you may receive a revenue stream for your donation"). Hence, the possibility of payments might be a disincentive to donate excess tissue for the good of science and hence for the good of society in general. Perhaps the most compelling of Truog's findings are in regard to the potential unfairness, should some tissue donors receive financial gain and others not. While all of the donors make the same contribution, it would only be due to the actions of the researchers that a few donors may receive rewards. This would be unfair distribution of financial gain to only those few who by no extra effort would have received a windfall, more akin to winning a lottery than making an altruistic contribution to science [34••].

\section{Biobanks: Use of Existing Stem Cell Lines for Therapeutic Products}

Whether existing hESC lines or specimens in biorepositories can be used as sources of pluripotent stem cells for therapy all comes back to the question - what did the donors consent to? In a 2012 survey of stewardship practices among biobanks in the USA, Henderson et al. found that of 314 biobanks that offer donors an "opt-in method," (i.e., opting in to having their specimens stored), $76 \%$ reported the use of global or broad consent for future research uses [36]. As stated in Aalto-Setala et al. [7••], transplantation of cells derived from iPS cells should perhaps get explicit consent, just as solid organs, tissues, or allogeneic cord blood are transplanted only with explicit consent of donors or their surrogates. While some individuals may be happy to donate to basic research, the concept that derivatives of their cells might someday be implanted into other individuals is a leap that bears specific consent. 


\section{Conclusion}

At the end of Tennessee Williams's play, "A Streetcar Named Desire," Blanche Dubois declares, "I have always depended on the kindness of strangers," [37]. With respect to the development of pluripotent stem therapies, we must likewise be cognizant of "the kindness of strangers." It is only through the kindness and generosity of embryo donors and somatic specimen donors that life-saving regenerative tissues may be developed. It is therefore incumbent on us who perform pluripotent stem cell research to be as informative and transparent as possible when consenting donors, recognizing their significant contribution, and our shared aspirational goals of improved health for all.

Acknowledgments I would like to thank the University of Washington Institute for Stem Cell and Regenerative Medicine and its generous benefactors who have provided non-federal funds in support of my work. Additionally, I am grateful to the generous IVF patients who have entrusted us with their excess frozen embryos as their contribution toward research on improving human health.

\section{Compliance with Ethics Guidelines}

Conflict of Interest Erica C. Jonlin declares that she has no conflict of interest.

Human and Animal Rights and Informed Consent This article does not contain any studies with animal subjects performed by the author.

Ethical approval: All procedures performed in studies involving human subjects were approved by the University of Washington Institutional Review Board, under Human Subjects Application no. 32659. Human subject activities were performed in accordance with the regulatory requirements laid down in U.S. Code of Federal Regulations, Title 45 Department of Health and Human Services Part 46, Protection of Human Subjects.

Informed consent: Informed consent was obtained from all individual participants included in the study.

\section{References}

Papers of particular interest, published recently, have been highlighted as:

- Of importance

•- Of major importance

1. Lund TC, Boitano AE, Delaney CS, Shpall EJ, Wagner JE. Advances in umbilical cord blood manipulation-from niche to bedside. Nat Rev Clin Oncol. 2014. doi:10.1038/nrclinonc.2014. 215. Published online 16 December 2014.

2. Pluripotent stem cells in translation: early decisions. NIH/FDA conference. March 21-22, 2011.

3. Code of Federal Regulations, Title 45 Department of Health and Human Services Part 46: protection of human subjects. Subpart A, basic HHS policy for protection of human research subjects. Revised January 15, 2009; Effective July 14, 2009. Available from: http://www.hhs.gov/ohrp/humansubjects/guidance/45cfr46.html.
4. Code of Federal Regulations, Title 21 Food and Drug Administration, Department of Health and Human Services Part 50: protection of human subjects. Subpart B, informed consent of human subjects. Revised as of April 1, 2014 Available from: http:// www.accessdata.fda.gov/scripts/cdrh/cfdocs/cfcfr/CFRSearch. cfm?CFRPart=50.

5. Guidance for Industry E6 good clinical practice: consolidated guidance. International Conference on Harmonization (ICH) E6 Available from: http://www.fda.gov/downloads/Drugs/Guidances/ ucm073122.pdf. April 1996.

6. NIH Guidelines for Human Stem Cell Research. Available from: http://stemcells.nih.gov/policy/pages/2009guidelines.aspx.

7.• Aalto-Setala K, Conklin BR, Lo B. Obtaining consent for future research with induced pluripotent cells: opportunities and challenges. PLoS Biol. 2009; 7(2). e42. doi:10.1371/journal.pbio. 1000042. The authors make carefully-considered recommendations for the content of donor consent forms for iPS cells.

8. International Society for Stem Cell Research. Guidelines for the clinical translation of stem cells. 2008. Available from: http://www.isscr. org/docs/default-source/clin-trans-guidelines/isscrglclinicaltrans.pdf.

9. NIH Stem Cell Registry. Available from: http://grants.nih.gov/ stem_cells/registry/current.htm.

10. Geron receives FDA clearance to begin world's first human clinical trial of embryonic stem cell-based therapy, posted Jan. 23, 2009. Available from: http:/www.drugs.com/news/geron-receives-fdaclearance-begin-world-s-first-human-clinical-trial-embryonicstem-cell-based-15771.html.

11. Asterias Biotherapeutics. Available from: http://asteriasbiotherapeutics. com/our-technology/stem-cells/.

12. Viacyte. Frequently Asked Questions. Available from: http:// viacyte.com/templates/frequently-asked-questions/.

13. Klimanskaya I, Chung Y, Becker S, Lu SJ, Lanza R. Human embryonic stem cell lines derived from single blastomeres. Nature. 2006;444:481-5. doi:10.1038/nature05142.

14.• Jonlin E. The voices of the embryo donors. Trends Mol Med. 2015;21:55-7. doi:10.1016/j.molmed.2014.11.007. This paper illustrates motivations of embryo donors and their keen interest in stem cell research and helping others.

15. Dasgupta I, Bollinger J, Mathews DJH, Neumann NM, Rattani A, Sugarman J. Patients' attitudes toward the donation of biological materials for the derivation of induced pluripotent stem cells. Cell Stem Cell. 2014;14:9-12. This study conducted focus groups of patients at Johns Hopkins Hospital regarding their opinions of stem cell research, and their concerns if they were asked to donate specimens. Patients were found to be supportive of research and wanted to help others.

16. Skloot R. The immortal life of Henrietta Lacks. New York: Crown Publishing Group; 2010.

17. Nisbet MC, Fahy D. Bioethics in popular science: evaluating the media impact of The Immortal Life of Henrietta Lacks on the biobank debate. BMC Med Ethics. 2013;14:10. http://www. biomedcentral.com/1472-6939/14/10.

18. Gymrek M, McGuire AL, Golan D, Halperin E, Erlich Y. Identifying personal genomes by surname inference. Science. 2013;339(6117):321-4. doi:10.1126/science.1229566.

19. American College of Medical Genetics and Genomics. ACMG Practice Guidelines. Incidental findings in clinical genomics: a clarification. Available from: https://www.acmg.net/docs/Incidental Findings_in_Clinical_Genomics_A_Clarification_081413.pdf and https://www.acmg.net/docs/IF Statement_Final 7.24.13.pdf.

20. Couzin-Frankel J. Genome sequencing: return of unexpected DNA results urged. Science. 2013;339(6127):1507-8. doi:10.1126/ science.339.6127.1507.

21. Riken - Press release. Pilot clinical study into iPS cell therapy for eye disease starts in Japan. July 30, 2013. Available from: http:// www.riken.jp/en/pr/press/2013/20130730_1/. 
22. Li HL, Fujimoto N, Sasakawa N, Shirai S, Ohkame T, Sakuma T, et al. Precise correction of the dystrophin gene in Duchenne muscular dystrophy patient induced pluripotent stem cells by TALEN and CRISPR-Cas9. Stem Cell Rep. 2015;4(1):143-54. doi:10. 1016/j.stemcr.2014.10.013.

23. Tomlinson T. Respecting donors to biobank research. Hastings Cent Rep. 2013;43(1):41-7. doi:10.1002/hast.115.

24. Hug K, Hermeren G, Johnasson M. Withdrawal from biobank research: considerations and the way forward. Stem Cell Rev Rep. 2012;8:1056-65. doi:10.1007/s12015-012-9399-y.

25. Mello MM, Wolf LE. The Havasupai Indian Tribe Case-lessons for research involving stored biologic samples. N Engl J Med. 2010;363(3):204-7. doi:10.1056/NEJMp1005203.

26. Samorinha C, Pereira M, Machado H, Figueiredo B, Silva S. Factors associated with the donation and non-donation of embryos for research: a systematic review. Hum Reprod Update. 2014;20(5): 641-55. doi:10.1093/humupd/dmu026.

27. Jonlin EC. Differing standards for the NIH Stem Cell Registry and FDA approval render most federally funded hESC lines unsuitable for clinical use. Cell Stem Cell. 2014;14(2):139-40. doi:10.1016/j. stem.2013.12.014.

28. U.S. Food and Drug Administration: Guidance for Industry. Eligibility determination for donors of human cells, tissues, and cellular and tissue-based products (HCT/Ps). 2007. Available from: http://www.fda.gov/BiologicsBloodVaccines/ GuidanceComplianceRegulatoryInformation/Guidances/Tissue/ ucm073964.htm.

29. Wilkerson A, Wongsatittham K, Johnston J. The NIH Stem Cell Registry: an absence of gamete donor consent. Cell Stem Cell. 2014;12:147-8. doi:10.1016/j.stem.2013.01.002.

30.• Saha K, Hogle LF. Allying with donors to link health and medical information with stem cell lines can advance diseases modeling while enhancing data access. Cell Stem Cell. 2014;14:559-60. This paper puts forth a model of partnerships between researchers and patients who donate specimens for disease modeling. Partnerships would include access to patient medical information, enhancing the research, as well as sharing results with donors, thereby building trust from the participants.

31. Kaye J, Curren L, Anderson N, Edwards K, Fullerton SM, Kanellopoulou N, et al. From patients to partners: participantcentric initiatives in biomedical research. Nat Rev Genet. 2012;13(5):371-6. doi:10.1038/nrg3218. This paper describes a model for long-term collaboration between specimen donors and researchers through the use of social media technologies.

32. Supreme Court of California. Moore v. Regents of University of California, 51 Cal.3d 120, July 9, 1990 Available from: http://www. eejlaw.com/materials/Moore_v_Regents_T08.pdf.

33. United States Court of Appeals, Eighth Circuit. Washington University, Appellee, v. William J. Catalona, MD, Appellant. Decided June 20, 2007.

34.• Truog RD, Kesselheim AK, Joffe S. Paying patients for their tissue: the legacy of Henrietta Lacks. Science. 2012;337:37-8. The authors describe their thought process when asked to consider the pros and cons of sharing revenues with patients who provide tissue for research. Their analysis includes consideration of the Henrietta Lacks legacy.

35. Sandel M. What money can't buy - the moral limits of markets. New York: Farrar, Straus, and Giroux; 2012.

36. Henderson GE, Edwards TP, Cadigan RJ, Davis AM, Zimmer C, Conlon I, et al. Stewardship practices of U.S. biobanks. Sci Transl Med. 2013;5(215):215cm7. www. ScienceTranslationalMedicine.org.

37. Williams T. A streetcar named desire. 1947. 